\title{
EFFECTS OF HYPOTHERMIA ON BRAIN GLUCOSE METABOLISM IN ACUTE LIVER FAILURE: A ${ }^{1} \mathrm{H} /{ }^{13} \mathrm{C}-$ NUCLEAR MAGNETIC RESONANCE STUDY
}

\author{
Nicolas Chatauret*, Claudia Zwingmann*, ${ }^{*}, 1$, Christopher Rose*, Dieter Leibfritz ${ }^{\dagger}$, \\ Roger F. Butterworth, *
} * Neuroscience Research Unit, CHUM Hôpital Saint-Luc, Montreal, Quebec, Canada † Department of Organic Chemistry, University of Bremen,
Bremen, Germany

\section{ABSTRACT}

Mild hypothermia has a protective effect on brain edema and encephalopathy in both experimental and human acute liver failure. The goals of the present study were to examine the effects of mild hypothermia $\left(35^{\circ} \mathrm{C}\right)$ on brain metabolic pathways using combined ${ }^{1} \mathrm{H}$ and ${ }^{13} \mathrm{C}$-Nuclear Magnetic Resonance (NMR) spectroscopy, a technique which allows the study not only of metabolite concentrations but also their de novo synthesis via cell-specific pathways in the brain. $:^{1} \mathrm{H}$ and ${ }^{13} \mathrm{C}$ NMR spectroscopy using $\left[1-{ }^{13} \mathrm{C}\right]$ glucose was performed on extracts of frontal cortex obtained from groups of rats with acute liver failure induced by hepatic devascularization whose body temperature was maintained either at $37^{\circ} \mathrm{C}$ (normothermic) or $35^{\circ} \mathrm{C}$ (hypothermic), and appropriate sham-operated controls. At coma stages of encephalopathy in the normothermic acute liver failure animals, glutamine concentrations in frontal cortex increased 3.5-fold compared to sham-operated controls $(P<0.001)$. Comparable increases of brain glutamine were observed in hypothermic animals despite the absence of severe encephalopathy (coma). Brain glutamate and aspartate concentrations were respectively decreased to $60.9 \% \pm 7.7 \%$ and $42.2 \% \pm 5.9 \%$ $(P<0.01)$ in normothermic animals with acute liver failure compared to control and were restored to normal values by mild hypothermia. Concentrations of lactate and alanine in frontal cortex were increased to $169.2 \% \pm 15.6 \%$ and $267.3 \% \pm 34.0 \%(P<0.01)$ respectively in normothermic rats compared to controls. Furthermore, de novo synthesis of lactate and alanine increased to $446.5 \% \pm 48.7 \%$ and $707.9 \% \pm 65.7 \%(P<0.001)$, of control respectively, resulting in increased fractional ${ }^{13} \mathrm{C}$-enrichments in these cytosolic metabolites. Again, these changes of lactate and alanine concentrations were prevented by mild hypothermia. Mild hypothermia $\left(35^{\circ} \mathrm{C}\right)$ prevents the encephalopathy and brain edema resulting from hepatic devascularization, selectively normalizes lactate and alanine synthesis from glucose, and prevents the impairment of oxidative metabolism associated with this model of ALF, but has no significant effect on brain glutamine. These findings suggest that a deficit in brain glucose metabolism rather than glutamine accumulation is the major cause of the cerebral complications of acute liver failure.

Abbreviations Ala, alanine; ALAT, alanine aminotransferase; ALF, acute liver failure; GABA, $\gamma$-aminobutyric acid; Gln, glutamine; HAL, hepatic artery ligation; HE, hepatic encephalopathy; Lac, lactate; LD, lactate dehydrogenase; MSO, methionine sulfoximine; NAA, $N$-acetyl-aspartate; NMR, nuclear magnetic resonance; PC, pyruvate carboxylase; PCA, portacaval anastomosis; PDH, pyruvate ehydrogenase; TCA cycle, tricarboxylic acid cycle

\section{INTRODUCTION}

The principal cause of mortality in patients with acute liver failure (ALF) is brain herniation resulting from intracranial hypertension caused by a progressive increase of brain water content. 1 The pathophysiologic mechanisms responsible for brain edema in ALF have not been fully elucidated; however, ammonia remains the prime candidate. Hyperammonemia is invariably observed in ALF, and a recent study revealed a significant correlation between arterial ammonia concentrations and the complication of brain herniation in patients with 
Chatauret, N. et al., 2003. Effects of hypothermia on brain glucose metabolism in acute liver failure: a H/C-nuclear magnetic resonance study. Gastroenterology, 125(3), p.815-824.

ALF. 2 Ammonia-related mechanisms that have been proposed to explain the encephalopathy and brain edema in ALF include direct electrophysiologic actions of the ammonium ion on excitatory/inhibitory neurotransmission, $\underline{3}$ osmotic effects resulting from the brain accumulation of the ammonia detoxification product glutamine $\underline{4}$ as well as effects of ammonia on cerebral energy metabolism, $\underline{5}$ astrocytic glutamate transport, $\underline{6}$ and glutamate (NMDA) receptors. $\underline{7}$ and $\underline{8}$

Mild hypothermia prevents brain edema in both experimental $\underline{10}$ and $\underline{11}$ and human $\underline{12}$ ALF. Not only do these findings herald the possibility of new approaches to the management of patients with ALF, they also provide an important research tool with which to investigate basic mechanisms responsible for brain edema and encephalopathy in ALF. The goals of the present study, therefore, were to study the effects of mild hypothermia $\left(35^{\circ} \mathrm{C}\right)$ on metabolic pathways in the brain derived from glucose metabolism, using combined ${ }^{1} \mathrm{H}$ and ${ }^{13} \mathrm{C}$-nuclear magnetic resonance (NMR) spectroscopy, a technique that facilitates the study not only of metabolite concentrations but also of their de novo synthesis via cell-specific pathways $\underline{13}$ in the brain.

\section{MATERIALS AND METHODS}

\section{Experimental animal model of ALF/surgical procedures}

ALF was induced in adult male Sprague-Dawley rats (175-200 g) by portacaval anastomosis (PCA) according to the guidelines of Lee and Fischer 14 followed by hepatic artery ligation (HAL). In brief, the rats were anesthetized with halothane, the inferior vena cava and portal vein were isolated, the inferior vena cava was partially clamped (anastomosis clamp, Roboz Instruments Inc, Washington, DC), and an elliptical piece of vein 1.5 times the portal vein diameter was removed. The portal vein was ligated and cut and an end-to-side anastomosis performed under a dissecting microscope. Total surgery time was less than 15 minutes. In sham-operated control rats, the inferior vena cava and portal vein were occluded for 15 minutes. Following surgery, all animals were housed individually under constant conditions of temperature, humidity, and light cycles and were allowed free access to standard laboratory chow and water. Overall mortality for shunted rats was less than 5\%. Forty-eight hours after PCA surgery, animals were anesthetized with halothane and subjected to hepatic artery ligation (HAL) or laparotomy (controls). Following $\mathrm{HAL}$, body temperatures were monitored continuously and maintained at either $35^{\circ} \mathrm{C}$ (hypothermic) or $37^{\circ} \mathrm{C}$ (normothermic) by means of thermal pads and heating lamps. Animals were assessed neurologically every 30 minutes during progression of ALF. Animals that could no longer right themselves after being placed on their backs were considered to be in precoma stage; animals in which both righting ability and corneal reflex could not be elicited were considered to be in coma. Hypothermic rats were killed at the same time post-HAL as the comatose normothermic rats. All animals received humane care according to the criteria outlined in the "Guide for the Care and Use of Laboratory Animals" prepared by the National Academy of Sciences and published by the National Institutes of Health (NIH publication 6-23, revised, 1985).

\section{Control of arterial glucose concentrations and administration of $[1-13 \mathrm{C}]$ glucose}

Arterial blood glucose levels were monitored every hour, and glucose was administered subcutaneously as needed to maintain normoglycemia. To ensure the same fractional ${ }^{13} \mathrm{C}$ enrichment in glucose entering the brain, blood glucose levels were measured immediately before administration of $\left[1{ }^{-13} \mathrm{C}\right]$ glucose $(6.62 \pm 0.49,6.48 \pm 0.52$, and $6.80 \pm 0.61$ $\mathrm{mmol} / \mathrm{L}$ in sham-operated controls, normothermic, and hypothermic ALF groups, respectively). After administration of $\left[1{ }^{-13} \mathrm{C}\right]$ glucose, the fractional enrichments in blood glucose $\left(\left[1-{ }^{13} \mathrm{C}\right] /\left[{ }^{12} \mathrm{C}\right]\right.$ glucose $)$, determined from ${ }^{1} \mathrm{H}-\mathrm{NMR}$ spectra, were not significantly different between the experimental groups $(24.55 \pm 2.05,25.09 \pm 1.81$, and $22.92 \pm$ 1.97 in sham-operated controls, normothermic, and hypothermic ALF groups, respectively).

\section{Preparation of brain extracts}

Sham-operated control rats and hepatic devascularized rats maintained at $37^{\circ} \mathrm{C}$ at coma stages (normothermic ALF rats) or at $35^{\circ} \mathrm{C}$ (hypothermic ALF rats) at comparable postsurgery time points were administered $\left[1-{ }^{13} \mathrm{C}\right]$ glucose (200 mg/kg, IP; Cambridge Isotope Laboratories) and killed 15 minutes later by decapitation. The bolus injection of

The final publication is available at http://dx.doi.org/10.1016/S0016-5085(03)01054-0 
glucose in unanesthetized rats was chosen to facilitate the study of metabolic changes in relation to neurologic status and to avoid hyperglycemic conditions. The blood was taken from the neck wound and immediately mixed with $20 \%$ perchloric acid. Forebrains were immediately frozen in isopentane $\left(a t-80^{\circ} \mathrm{C}\right)$, dissected over dry ice for the frontal cortex, and frozen in liquid nitrogen. The samples were powdered over liquid nitrogen. Blood and tissue samples were extracted with $12 \%$ perchloric acid as previously described. 13

\section{Brain water measurement}

Water content of the brain (percentage) was measured gravimetrically using a density gradient of bromobenzenekerosene precalibrated with $\mathrm{K}_{2} \mathrm{SO}_{4}$ as previously described.15 Eight measurements were made per animal, and values were arithmetically averaged.

\section{Ammonia measurement}

Plasma and cerebrospinal fluid ammonia concentrations were estimated using a commercial ammonia test kit, which uses an ion-exchange method, followed by colorimetric measurement of ammonia nitrogen with the Bertholet phenate-hypochlorate reaction ( $\mathrm{n}=8$ in each experimental group). $\underline{16}$

\section{NMR spectroscopy}

The lyophilized extracts of brain tissue and blood plasma were dissolved in $0.6 \mathrm{~mL} \mathrm{D}_{2} \mathrm{O}$ and centrifuged. The $\mathrm{pH}$ was adjusted to 7.0 with DCl and NaOD. ${ }^{1} \mathrm{H}$ - and ${ }^{13} \mathrm{C}$-NMR spectra were recorded on Bruker DRX 600 or AVANCE NB/WB360 spectrometers, operating at frequencies of $600 \mathrm{MHz}$ or $360 \mathrm{MHz}$ for ${ }^{1} \mathrm{H}$ measurements and $150.9 \mathrm{MHz}$ or $90.5 \mathrm{MHz}$ for ${ }^{13} \mathrm{C}$ measurements. ${ }^{1} \mathrm{H}-\mathrm{NMR}$ spectra were recorded with a 5-mm H,C,N inverse triple resonance probe, 400 accumulations, repetition time 15 seconds, spectral width $7183 \mathrm{~Hz}$ (DRX 600) or $3623 \mathrm{~Hz}$ (AM/AMX 360). Chemical shifts were referenced to lactate at $1.33 \mathrm{ppm} .{ }^{13} \mathrm{C}-\mathrm{NMR}$ spectra were recorded with a $5-\mathrm{mm}{ }^{1} \mathrm{H} /{ }^{13} \mathrm{C}$ dual probe, 10,000 accumulations, repetition time 2.5 seconds, composite pulse decoupling with WALTZ-16, and spectral width $47,619 \mathrm{~Hz}$ (DRX 600) or 20,833 Hz (AM/AMX 360). Chemical shifts were referenced to the C-3 signal of lactate at $21.3 \mathrm{ppm}$.

\section{Measurement of metabolite concentrations}

Lactate concentrations were determined enzymatically (adapted for measurement in 96-well microtiter ELISA plates) using a commercially available kit (Roche Molecular Biochemicals, Mannheim, Germany). The concentrations ( $\mu \mathrm{mol} / \mathrm{g}$ tissue) of other unlabeled metabolites and their pool sizes $\left(\left[{ }^{13} \mathrm{C}\right]+\left[{ }^{12} \mathrm{C}\right]\right)$ were determined from fully relaxed ${ }^{1} \mathrm{H}-\mathrm{NMR}$ spectra of blood and brain extracts, obtained after injection of $\left[1-{ }^{13} \mathrm{C}\right]$ glucose or equivalent amounts of unlabeled glucose, using the known lactate concentrations as an internal standard.

\section{Calculation of fractional ${ }^{13} \mathrm{C}$ enrichments}

The fractional ${ }^{13} \mathrm{C}$ enrichment in lactate was calculated as the ratio of $\left[3^{-13} \mathrm{C}\right]$ lactate to unlabeled lactate by integration of the peak areas of the methyl groups in ${ }^{1} \mathrm{H}-\mathrm{NMR}$ spectra (Figure 1):

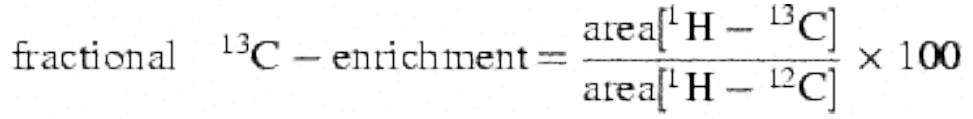

The values were corrected for $1.1 \%$ natural abundance ${ }^{13} \mathrm{C} .{ }^{13} \mathrm{C}$ enrichments in $\left[1-{ }^{13} \mathrm{C}\right]$ glucose were calculated accordingly using the $\mathrm{H} 1 \alpha$ glucose resonances in ${ }^{1} \mathrm{H}-\mathrm{NMR}$ spectra. The fractional ${ }^{13} \mathrm{C}$ enrichment of each carbon of other metabolites was derived from peak area ratio of the ${ }^{13} \mathrm{C}$-labeled carbon/natural abundance carbon and using the known ${ }^{13} \mathrm{C}$ enrichment of lactate as internal standard as described in detail previously. 13 and 17 The absolute amount of ${ }^{13} \mathrm{C}$ in a specified carbon position (absolute synthesis from $\left[1{ }^{-13} \mathrm{C}\right]$ glucose; $\mu \mathrm{mol} / \mathrm{g}$ wet weight) is the concentration of the unlabeled metabolite times the fractional ${ }^{13} \mathrm{C}$ enrichment. 


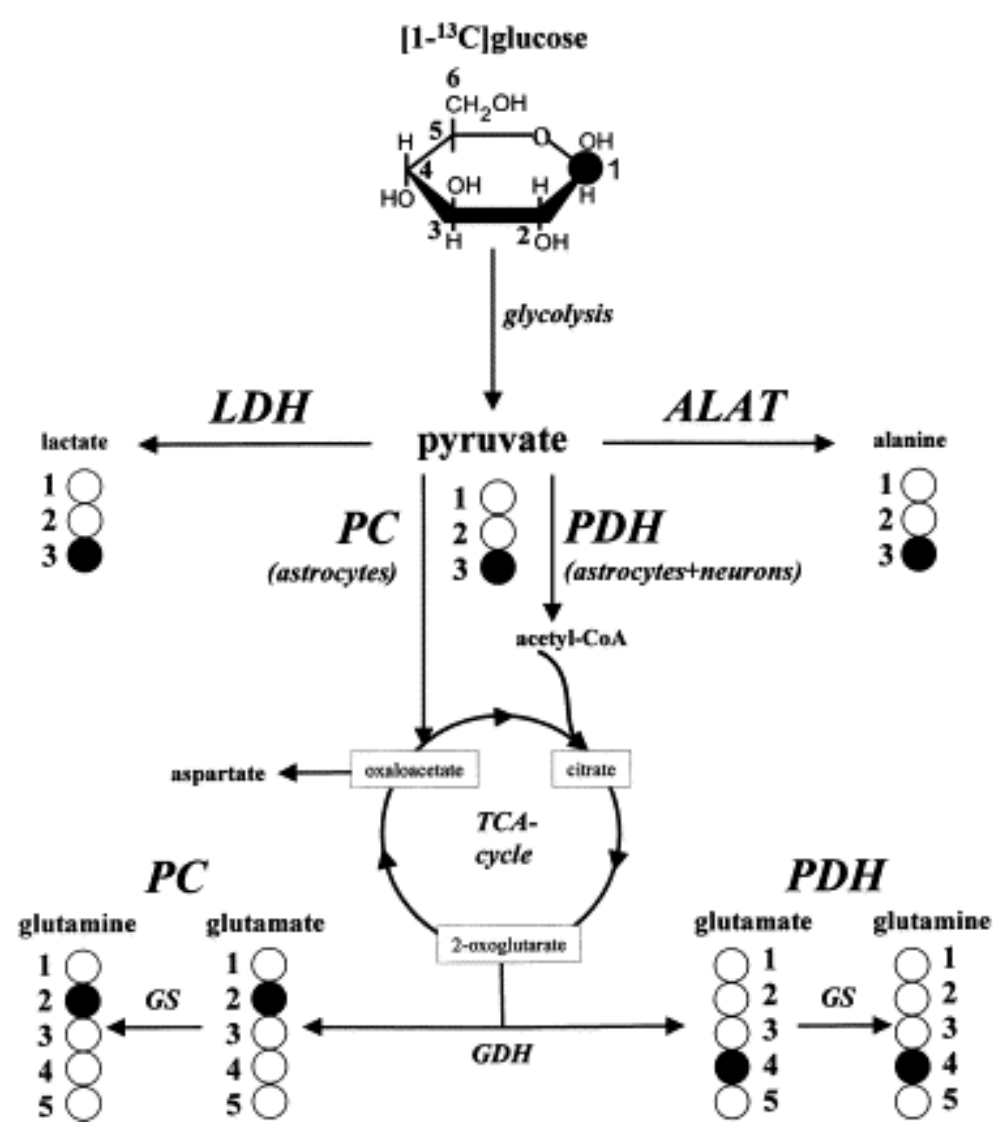

Figure 1. Labeling of metabolites from $\left[1^{-13} \mathrm{C}\right]$ glucose: label distribution in glycolytic and TCA cycle intermediates during metabolism of $\left[1-{ }^{13} \mathrm{C}\right]$ glucose. A single turn of the TCA cycle from pyruvate via pyruvate carboxylase (PC) or pyruvate dehydrogenase (PDH) to 2-oxoglutarate and subsequently glutamate and glutamine is considered. A description of the pathways leading to the different isotopomers is provided in the text. LDH, lactate dehydrogenase; ALAT, alanine aminotransferase; GAD, glutamate decarboxylase; $\mathrm{GDH}$, glutamate dehydrogenase; GS, glutamine synthetase.

\section{Theoretical labeling of metabolites from $\left[1^{-13} \mathrm{C}\right]$ glucose}

The metabolic pathways whereby the ${ }^{13} \mathrm{C}$ label from $\left[1-{ }^{13} \mathrm{C}\right]$ glucose is transformed into various metabolites are presented schematically in Figure 1. 17 Briefly, via the glycolytic pathway, [1-13C]glucose is transformed to [313C]pyruvate and subsequently to [3-13C]alanine and [3-13C]lactate. [3-13C]Pyruvate may then enter the TCA cycle via the anaplerotic pathway (pyruvate carboxylase [PC] or malic enzyme [ME]) or via the oxidative pathway (pyruvate dehydrogenase; PDH). Via PC, glutamate and glutamine are labeled at C-2. In the oxidative pathway, pyruvate enters the cycle as [2-13C] acetyl-CoA, and glutamate and glutamine are monolabeled at C-4. The ratio of C4/C2 in glutamate and glutamine was used to estimate the relative contribution of the PDH vs. the PC pathway. The order of labeled carbons is reversed in $\gamma$-aminobutyric acid (GABA) (i.e., the labels in [2(4)-13C]glutamate end up in [4(2)-13C]GABA) (not shown in Figure 1). Because we did not observe double-labeled isotopomers, only 1 TCA cycle turn is shown in Figure 1. Isotopomers arising from scrambling of the label within the TCA cycle are omitted for clarity.

\section{Statistical analysis}

The NMR studies were carried out with sham-operated controls $(n=6)$ and 12 hepatic devascularized rats $(n=6$ normothermic ALF rats and $n=6$ hypothermic ALF rats). Data are expressed as mean \pm SD. Data between individual groups were analyzed using ANOVA and post hoc Tukey's test. Differences were considered significant when $P<0.05$ 
Chatauret, N. et al., 2003. Effects of hypothermia on brain glucose metabolism in acute liver failure: a H/C-nuclear magnetic resonance study. Gastroenterology, 125(3), p.815-824.

(†significantly different from sham-operated controls; ${ }^{\dagger}$ significantly different between hypothermic and normothermic ALF groups; $* * * P<0.001 ; * * P<0.01, * P<0.05$ ).

\section{RESULTS}

Following hepatic devascularization, normothermic ALF rats $(n=8)$ developed progressive encephalopathy consisting of loss of activity, loss of righting ability (precoma stage), and loss of corneal reflex (coma stage at 13.4 \pm 1.1 hours). At times when the normothermic ALF rats were comatose, none of the hypothermic ALF $(n=8)$ rats had developed significant neurologic symptoms. Hypothermic ALF rats eventually became comatose at $18.3 \pm 1.1$ hours post-HAL, confirming a previous report. 9 Plasma ammonia levels were not significantly different between the 2 groups at any time point studied (Table 1), whereas CSF ammonia concentrations were significantly less (by $34 \%, \mathrm{P}$ $<0.01, \mathrm{n}=8$ ) in the hypothermic than in the normothermic ALF group at coma stages of encephalopathy ( $672 \pm 73$ $\mu \mathrm{g} / \mathrm{dL}$ vs. $1007 \pm 78 \mu \mathrm{g} / \mathrm{dL}$ ) (Table 1 ). Normothermic ALF rats manifested increased brain water content, whereas mild hypothermia led to a significant attenuation of this increase (sham, $80.22 \% \pm 0.12 \%$; normothermic ALF rats, $81.74 \% \pm 0.13 \%$; hypothermic ALF rats, $80.48 \% \pm 0.15 \% ; \mathrm{P}<0.01$ compared with the normothermic ALF group, $\mathrm{n}=$ 8 in each experimental group) (Table 1 ).

Table 1. Plasma and CSF Ammonia and Brain Water Content in ALF Rats

\begin{tabular}{|c|c|c|c|}
\hline & Sham & $\begin{array}{l}\text { Normothermic } \\
\text { ALF rats }\end{array}$ & $\begin{array}{l}\text { Hypothermic } \\
\text { ALF rats }\end{array}$ \\
\hline Plasma ammonia $(\mu g / d L)$ & $64.7 \pm 9.5$ & $640 \pm 33.8^{a b}$ & $585.7 \pm 34.2^{a, b}$ \\
\hline CSF ammonia $(\mu g / d L)$ & $52.4 \pm 9.5$ & $1007 \pm 77.8^{a b}$ & $671 \pm 72.8^{-d}$ \\
\hline Brain water content (\%) & $80.22 \pm 0.12$ & $81.74 \pm 0.13^{a b}$ & $80.48 \pm 0.15^{a-d}$ \\
\hline
\end{tabular}

NOTE. Plasma and CSF ammonia, as well as brain water content, were determined as described in the text in sham-operated control rats $(n=$ 8 ), and rats with ALF were maintained at $37^{\circ} \mathrm{C}$ (ALF-coma) $(n=8)$ or $35^{\circ} \mathrm{C}$ (ALF hypothermia) $(n=8)$. Values represent means $\pm S D\left({ }^{a}\right.$ Significantly different from sham-operated controls; ${ }^{c}$ significant differences between hypothermic and normothermic groups; ${ }^{b} P<0.001 ;{ }^{d} P<0.05$; ns, not significant; by ANOVA).

\section{Brain amino acid concentrations}

The concentrations of amino acids related to the TCA cycle and neurotransmitter metabolism, i.e., glutamine, glutamate, GABA, aspartate as well as the neuronal marker molecule $\mathrm{N}$-acetyl-aspartate (NAA) in frontal cortex, were calculated from ${ }^{1} \mathrm{H}-\mathrm{NMR}$ spectra Figure 2 and Figure 3. At coma stages (10-12 hours after HAL), glutamine concentrations were significantly increased both in the normothermic and the hypothermic rats compared with controls (to $374 \% \pm 31.0 \%, P<0.001$ and $387 \% \pm 49.0 \%, P<0.001$, respectively; $\mathrm{n}=6$ ). Glutamate, aspartate, and NAA concentrations in frontal cortex were decreased in normothermic rats to $60.9 \% \pm 7.7 \%(P<0.01), 42.2 \% \pm 5.9 \%$ $(P<0.001)$, and $70.7 \% \pm 7.0 \%(P<0.01)$, respectively, but normalized to control values under hypothermic conditions. GABA levels were unchanged in both normothermic and hypothermic ALF rats.

\section{Synthesis of lactate and alanine}

In normothermic rats, ALF resulted in an increase of lactate and alanine concentrations $\left(\left[{ }^{12} \mathrm{C}\right]+\left[{ }^{13} \mathrm{C}\right]\right)$ to $169.2 \% \pm$ $15.6 \%$ and $267.3 \% \pm 34.0 \%(P<0.001)$, respectively, which were both significantly attenuated by mild hypothermia (increase to $131.1 \% \pm 16.6 \%$ and $154.2 \% \pm 18.6 \%$, respectively) ( 6 animals were used in each group) Figure 4 and Figure 5. Furthermore, the resonance attributed to 13C-labeled lactate (synthesized from [1-13C]glucose) can be distinguished from the unlabeled isotopomer (synthesized from substrates other than [1-13C]glucose) (Figure 4). During coma stages of encephalopathy, the concentration of 13C-labeled lactate increased to a much higher concentration (to $446.5 \% \pm 48.7 \%$, compared with sham-operated controls, $P<0.001$ ) compared to its total, resulting in 3-fold increased fractional ${ }^{13} \mathrm{C}$ enrichments in lactate. In hypothermic ALF rats, de novo synthesized ${ }^{13} \mathrm{C}$ labeled lactate was not significantly different from sham-operated control values. Thus, hypothermia led to a selective reduction of de novo synthesis of ${ }^{13} \mathrm{C}$-labeled lactate $(P<0.001)$. No significant changes in $\left[3-{ }^{13} \mathrm{C}\right]$ lactate were observed in blood plasma of ALF rats 15 minutes after injection of $[1-13 \mathrm{C}] \operatorname{glucose}(n=6)$. 

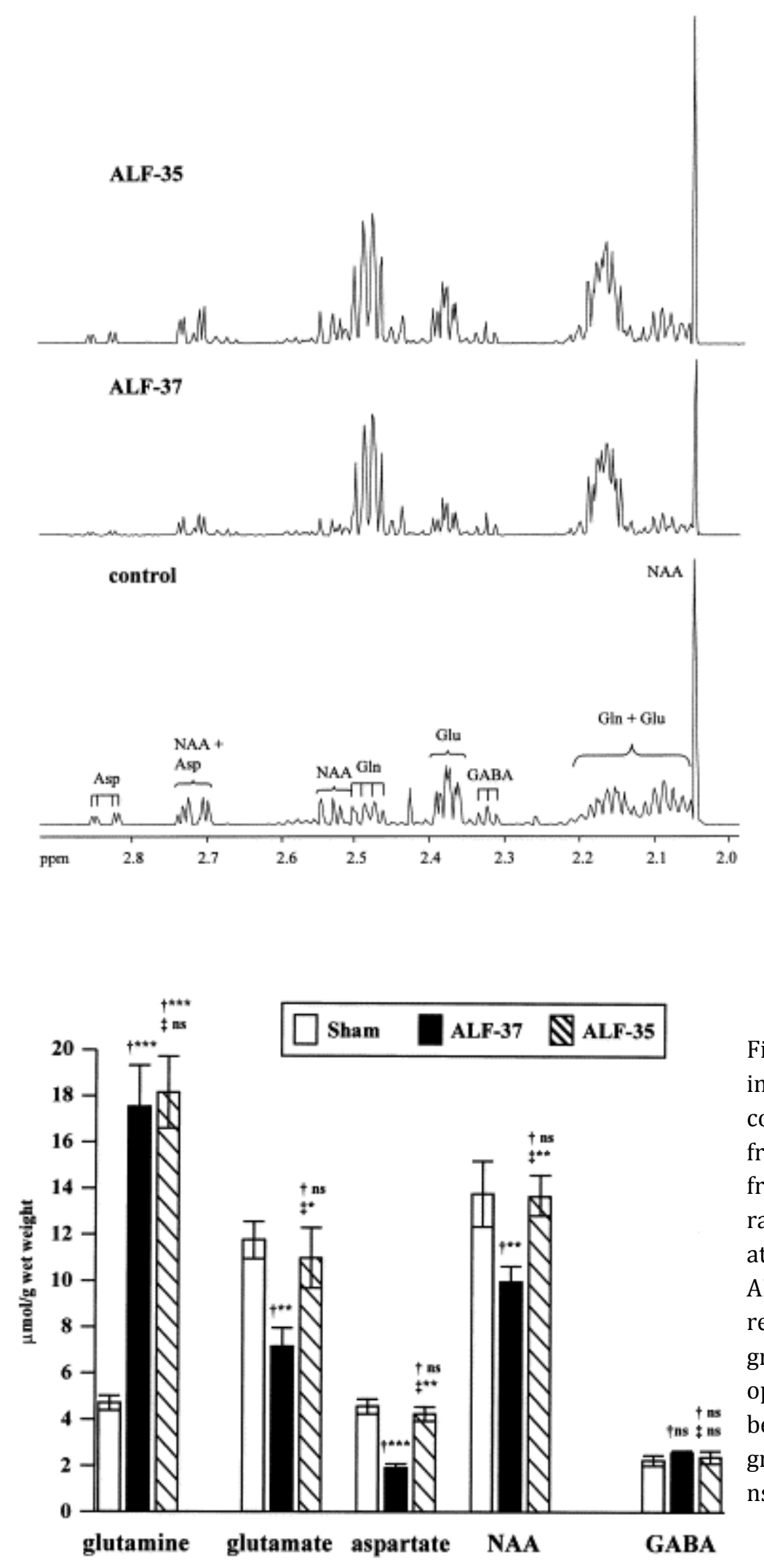

Figure 2. ${ }^{1} \mathrm{H}-\mathrm{NMR}$ spectra of brain extracts in ALF: effect of hypothermia. Figure shows typical segments of ${ }^{1} \mathrm{H}-\mathrm{NMR}$ spectra of extracts obtained from frontal cortex of a sham-operated control rat compared with rats with ALF maintained at either $37^{\circ} \mathrm{C}$ (ALF-coma) or $35^{\circ} \mathrm{C}$ (ALF-hypothermia). Peak assignments: GABA, $\gamma$-aminobutyric acid; Glu, glutamate; Gln, glutamine; NAA, $\mathrm{N}$-acetyl-aspartate; Asp, aspartate.

Figure 3. Concentrations of brain amino acids in ALF: effect of hypothermia. Figure shows concentrations of amino acids, calculated from ${ }^{1} \mathrm{H}-\mathrm{NMR}$ spectra of extracts obtained from frontal cortex of sham-operated control rats $(n=6)$ and of rats with ALF maintained at $37^{\circ} \mathrm{C}$ at coma stage $(\mathrm{n}=6)$ and rats with ALF maintained at $35^{\circ} \mathrm{C}(\mathrm{n}=6)$. Values represent means \pm SD for $n=6$ animals per group ( ${ }^{\dagger}$ significantly different from shamoperated controls; 'significantly different between hypothermic and normothermic groups; $* * * P<0.001 ; * * P<0.01 ; * P<0.05$; $n s$, not significant by ANOVA). 


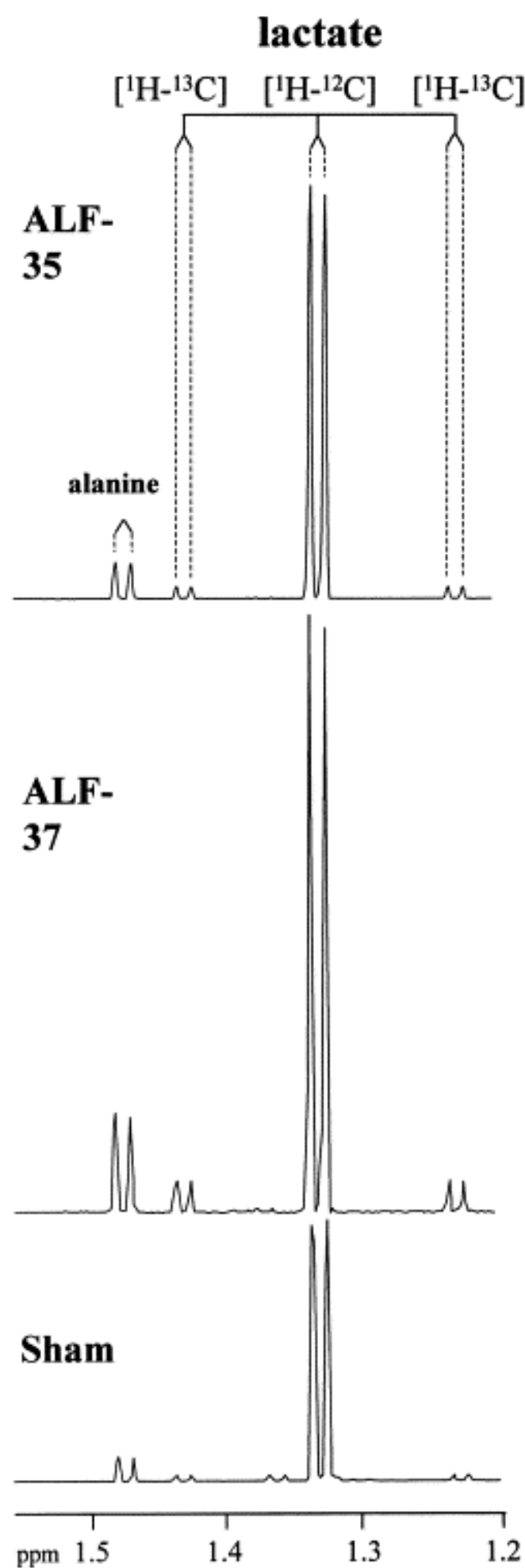

\section{${ }^{13}$ C-enrichment $(\%)=$ area $\left[{ }^{1} \mathrm{H}^{-13} \mathrm{C}\right]$ lactate $\mathbf{x} 100$ \\ area $\left(\left[{ }^{1} \mathbf{H}-{ }^{12} \mathrm{C}\right]+\left[{ }^{1} \mathbf{H}-{ }^{13} \mathbf{C}\right]\right.$ lactate $)$}

$\left[3-{ }^{13}\right.$ C $]$ lactate

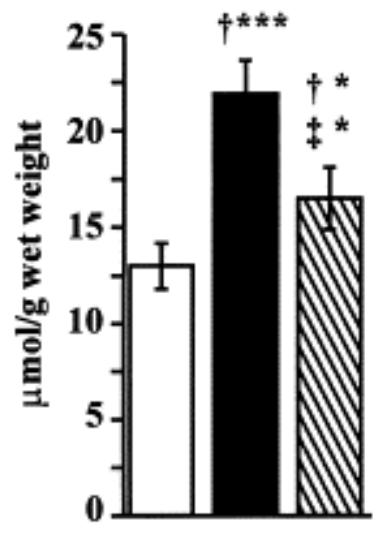

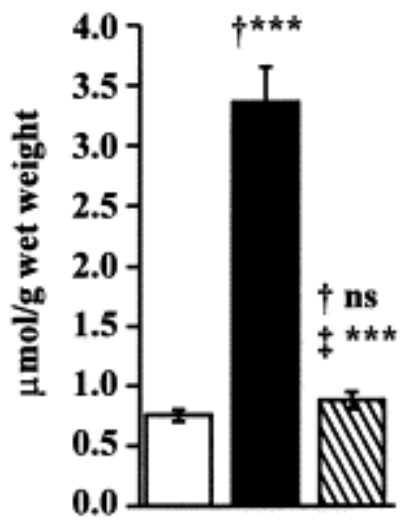

ALF-37 ALF-35

\section{fractional ${ }^{13}$ C-enrichment in lactate (\%)}

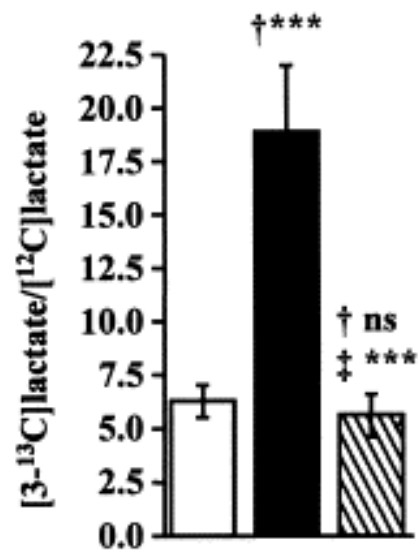

Figure 4. Brain lactate synthesis in ALF: effect of hypothermia. Left: segments of ${ }^{1} \mathrm{H}-\mathrm{NMR}$ spectra of extracts from frontal cortex of a sham-operated control rat compared with rats with ALF maintained at $37^{\circ} \mathrm{C}$ (ALF coma) or $35^{\circ} \mathrm{C}$ (ALF hypothermia). The percentage ${ }^{13} \mathrm{C}$ enrichment in lactate (indicating de novo synthesis) was calculated according to the formula in the upper right. Bottom, right: Changes in the concentrations, 
amounts of ${ }^{13} \mathrm{C}$-labeled lactate, and fractional ${ }^{13} \mathrm{C}$ enrichments in lactate in rats with ALF compared with sham-operated control rats. For statistical analysis, see legend to Figure 3.

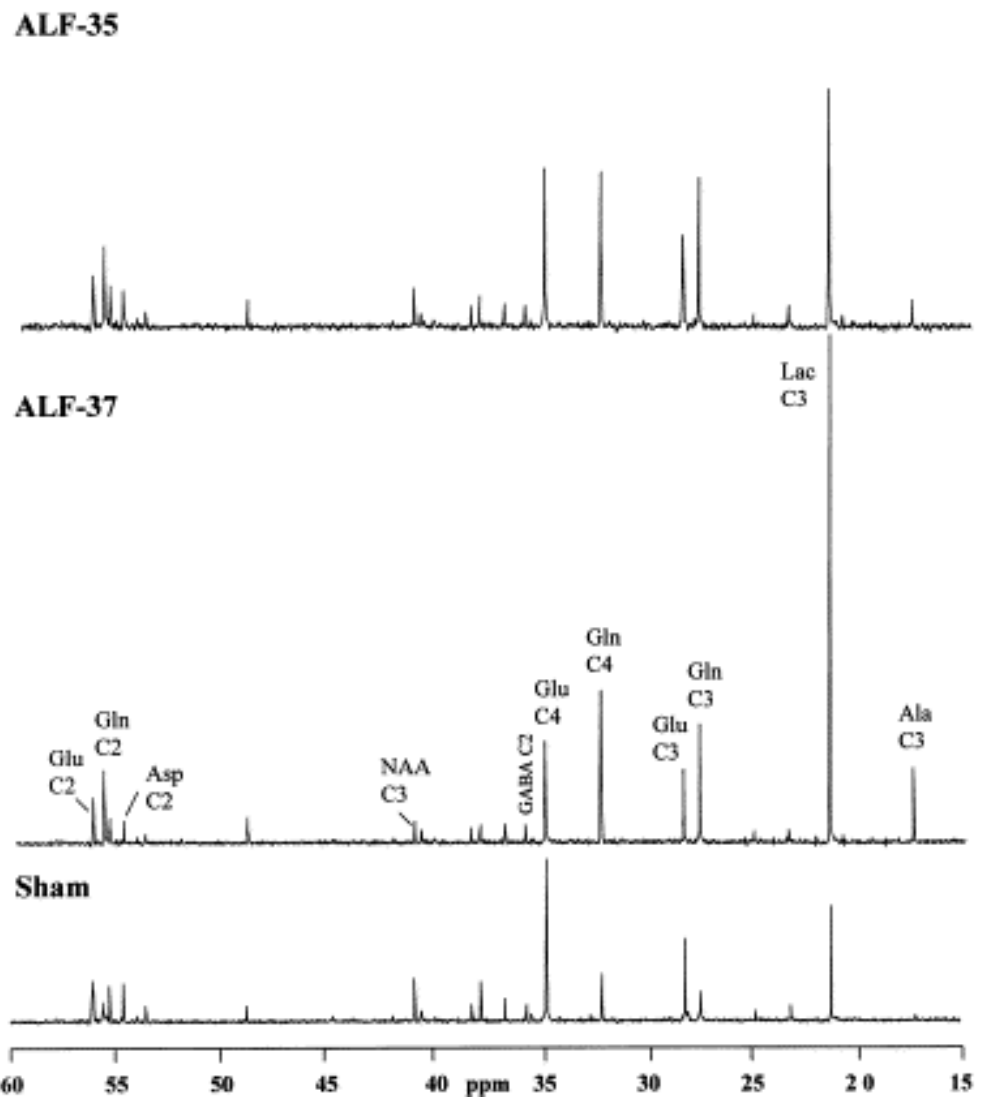

Figure $5 .{ }^{13} \mathrm{C}$-NMR spectra of brain extracts from rats with ALF: effect of hypothermia. Figures shows ${ }^{13} \mathrm{C}$ NMR spectra of extracts from frontal cortex of a sham-operated control rat compared with rats with ALF maintained at $37^{\circ} \mathrm{C}$ (ALF coma) or $35^{\circ} \mathrm{C}$ (ALF-hypothermia) 15 minutes after injection of $\left[1-{ }^{13} \mathrm{C}\right]$ glucose. Peak assignments: Ala, alanine; GABA, $\gamma$-aminobutyric acid; Glu, glutamate; Gln, glutamine; Lac, lactate; NAA, $\mathrm{N}$-acetyl-aspartate (signals assigned NAA are due to naturally abundant ${ }^{13} \mathrm{C}$-labelled NAA).

${ }^{13} \mathrm{C}$-labeled alanine was quantified from ${ }^{13} \mathrm{C}$-NMR spectra (Figure 5 ). As observed for lactate, ALF resulted in a marked increase of de novo synthesis of $\left[3-{ }^{13} \mathrm{C}\right]$ alanine to $707.9 \pm 65.7(P<0.001 ; \mathrm{n}=6)$ at coma stages, which was significantly reduced by hypothermia (increased to $171.1 \% \pm 20.7 \% ; n=6$ ). Interestingly, the fractional ${ }^{13} \mathrm{C}$ enrichment in $\left[{ }^{3-13} \mathrm{C}\right]$ alanine was increased under normothermic conditions but remained within normal limits in hypothermic animals $(n=6)$. The preferential increase of ${ }^{13} \mathrm{C}$ labeling and the selective protective effect of hypothermia on elevated ${ }^{13} \mathrm{C}$ label incorporation from $\left[1-{ }^{13} \mathrm{C}\right]$ glucose into alanine closely resembles the changes observed for ${ }^{13} \mathrm{C}$-labeled lactate.

\section{Labeling of tricarboxylic acid cycle-related metabolites from [1-13C]glucose}

Synthesis of glutamine, glutamate, and GABA ${ }^{13} \mathrm{C}$ resonances were quantified from ${ }^{13} \mathrm{C}$-NMR spectra (Figure 6). Six animals were used in each group (sham-operated controls, normothermic ALF rats, and hypothermic ALF rats) for 13C-NMR analysis. The total amounts of $13 \mathrm{C}$ label ( $\mu \mathrm{mol} / \mathrm{g}$ tissue) and the fractional 13C enrichments $(\%)$ in these amino acids are presented in Figure 7. The increase in de novo synthesis of glutamine from [1-13C]glucose is much higher than the increase of its pool size at coma stages. 13C isotopomer analysis of the individual carbon positions in glutamine revealed a greater increase of C-2-labeled glutamine (to $718.5 \% \pm 16.7 \%$ of control, $P<0.001$ ) compared with C-4 (to $500.8 \% \pm 80.3 \%$ of control, $P<0.001$ ). Unlike the selective prevention of abnormal lactate synthesis 
from $\left[1-{ }^{13} \mathrm{C}\right]$ glucose by mild hypothermia, the increase of ${ }^{13} \mathrm{C}$-labeled glutamine did not differ significantly between normothermic and hypothermic ALF groups. In normothermic ALF rats, a relatively higher decrease of [4${ }^{13} \mathrm{C}$ ]glutamate (through the PDH pathway) compared with its pool size resulted in a decreased relative ${ }^{13} \mathrm{C}$ enrichment in C-4 of glutamate to $62.3 \% \pm 10.7 \%$ of control $(P<0.001)$. Although hypothermia failed to prevent the increased glutamine synthesis, it led to a complete recovery selectively of PDH-mediated glutamate synthesis. The prevention of impaired flux of glucose through PDH by hypothermia is reflected also by the prevention of the decrease in the ratio of $\mathrm{C}-4 / \mathrm{C}-2$ in glutamate (but without significant changes of $\mathrm{C}-4 / \mathrm{C}-2$ in glutamine in hypothermic compared with normothermic rats), which was calculated as a measure of the relative glucose oxidative metabolism (vs. the anaplerotic pathway) (Figure 8). No changes were observed for de novo synthesized GABA in either normothermic or hypothermic groups of rats with ALF (data not shown).

total alanine

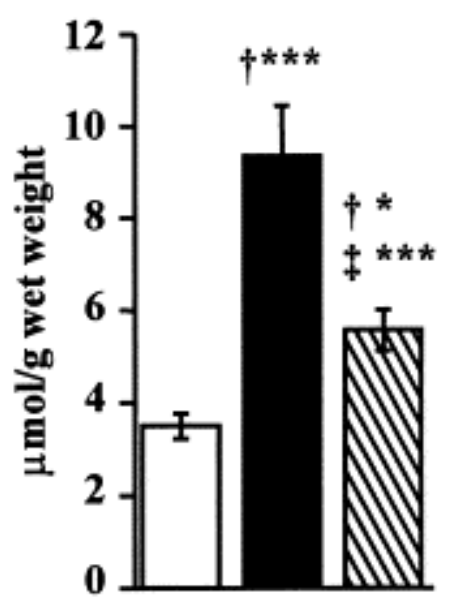

[3-13 C]alanine

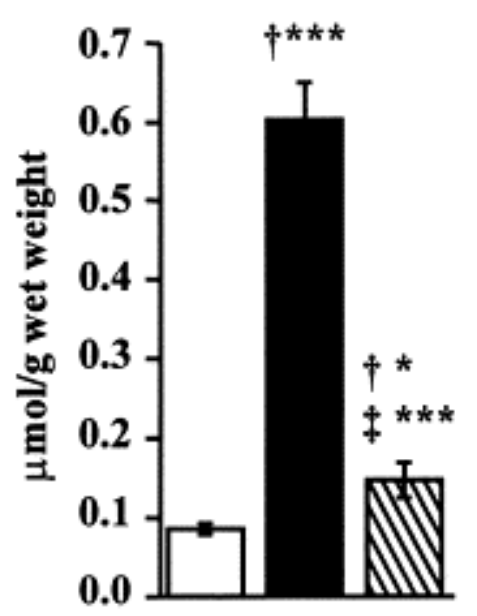

Figure 6. Brain alanine synthesis in ALF: effect of hypothermia. Figure shows changes in the concentration, amount of ${ }^{13} \mathrm{C}$-labeled alanine, and fractional ${ }^{13} \mathrm{C}$ enrichments in alanine in frontal cortex of rats with ALF maintained at $37^{\circ} \mathrm{C}$ (ALFcoma) or $35^{\circ} \mathrm{C}$ (ALF-hypothermia) compared with sham-operated controls. For statistical analysis, see legend to Figure 3.

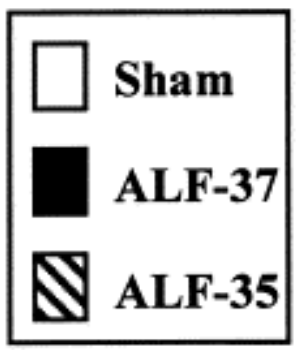

\section{fractional ${ }^{13} \mathrm{C}$-enrichment in alanine (\%)}

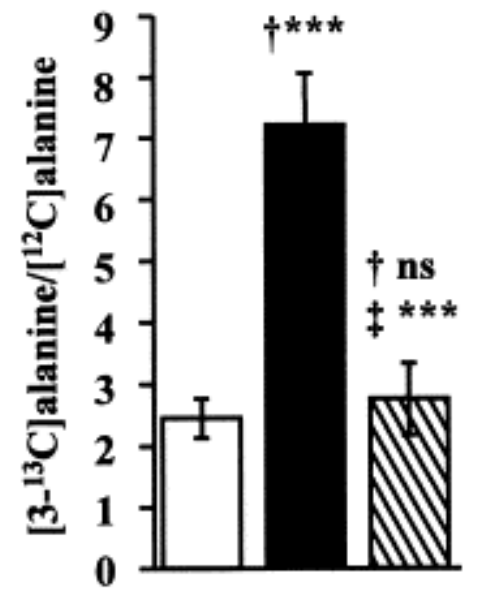




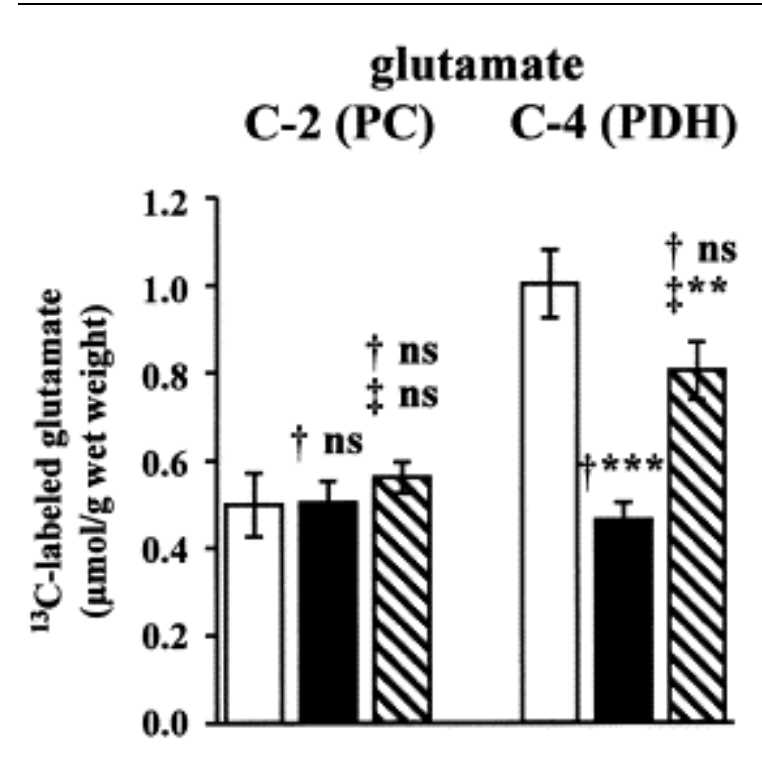

\section{glutamate \\ C-2 (PC) C4 (PDH)}

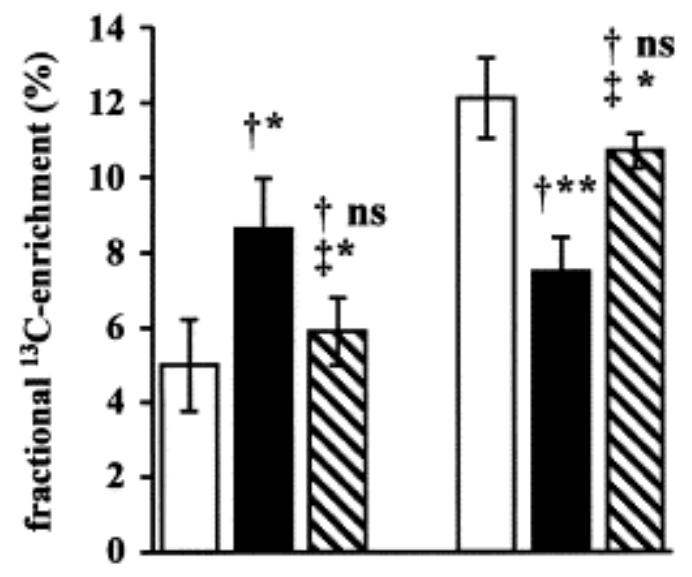

ALF-37

AN ALF-35
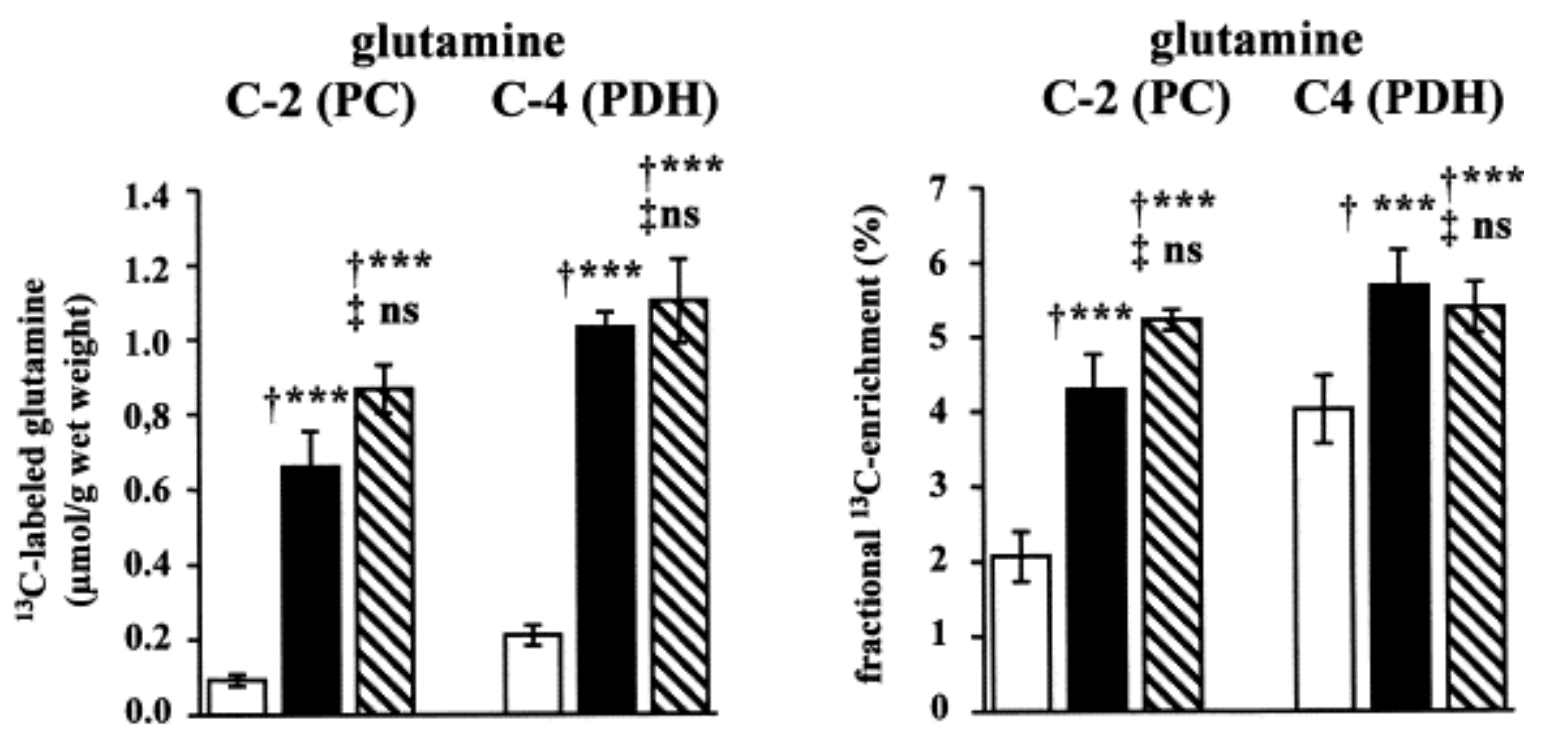

Figure 7. Synthesis of brain glutamate and glutamine in ALF: effect of hypothermia. Figure shows changes in the absolute amounts of ${ }^{13} \mathrm{C}\left(\mu \mathrm{mol} / \mathrm{g}\right.$ tissue) $(l e f t)$ and in the percentage of ${ }^{13} \mathrm{C}$ enrichments (right) in individual carbon positions (via the PC- and PDH pathways) of glutamate and glutamine labeled 15 minutes after injection of $\left[1-{ }^{13} \mathrm{C}\right]$ glucose, calculated from ${ }^{13} \mathrm{C}$-NMR spectra of extracts from frontal cortex of rats with ALF maintained at $37^{\circ} \mathrm{C}$ (ALF coma) or $35^{\circ} \mathrm{C}$ (ALF hypothermia) compared with sham-operated controls. For statistical analysis, see legend to Figure 3. 


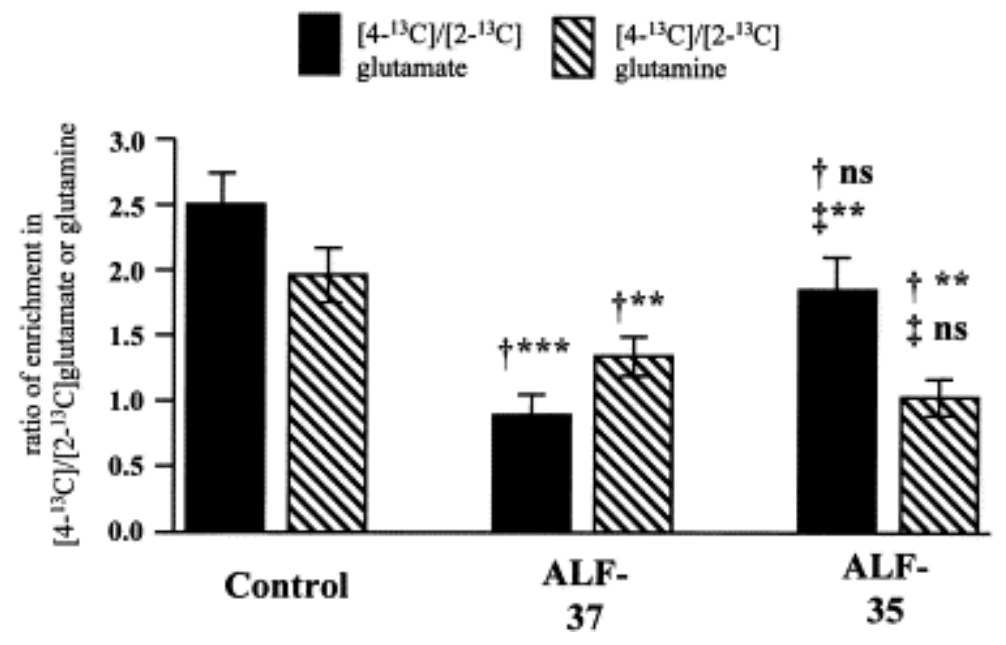

Figure 8. Relative contribution of carbon flux through PDH and PC. Ratios of C-4/C-2 of glutamate and glutamine from ${ }^{13} \mathrm{C}$-NMR spectra of extracts from frontal cortex of sham-operated control rats compared with rats with ALF maintained at $37^{\circ} \mathrm{C}$ (ALF coma) or $35^{\circ} \mathrm{C}$ (ALF hypothermia). For statistical analysis, see legend to Figure 3.

\section{DISCUSSION}

Results of the present study reveal that mild hypothermia delays the onset of encephalopathy and brain edema and selectively prevents alterations in energy and glucose metabolism in frontal cortex of rats with experimental ALF. In particular, hypothermia prevents the increase in brain lactate. These findings add to an accumulating body of evidence to suggest that increased brain lactate production is causally related to the encephalopathy and brain edema in ALF. Other evidence in support of this possibility includes the report of a significant correlation between brain lactate concentrations and both encephalopathy grade $\underline{18}$ and EEG changes $\underline{19}$ in experimental ALF. Results of in vitro studies support a key role of lactate in the pathogenesis of astrocyte swelling. For example, it was previously shown that exposure of primary cultures of rat astrocytes (the cell type shown to selectively exhibit swelling in the brain in ALF) to pathophysiologically relevant concentrations of lactate leads to significant swelling. $20 \mathrm{~A}$ recent report advocated the use of a noninvasive technique to measure brain lactate in vivo as an evaluation of advanced encephalopathy in ALF.21 Results of the present study now show that the selective attenuation of ALF-related increases of lactate and alanine in frontal cortex, concomitant with the prevention of encephalopathy and brain edema, resides in the ability of hypothermia to prevent the de novo synthesis of lactate from glucose.

It should be borne in mind, however, that, although there is convincing evidence, both from the present and previous studies, for decreased glucose oxidation and lactate/alanine accumulation in the brain in ALF, there is no evidence to suggest that either encephalopathy or brain edema are consequences of diminished ATP synthesis. $\underline{22}, \underline{23}$ and $\underline{24}$ The present ${ }^{13} \mathrm{C}$-NMR spectroscopic study is novel by virtue of its ability to differentiate between metabolite concentrations and metabolic fluxes. In particular, the present findings suggest that one important mechanism of action of hypothermia in ALF is the facilitation of pyruvate oxidation as a consequence of decreased blood-brain transfer of ammonia, which has been shown to inhibit the tricarboxylic acid cycle (TCA) enzyme $\alpha$-ketoglutarate dehydrogenase. 25 Increased glycolytic activity has then compensated to maintain ATP production with consequent increases of brain lactate and alanine.

Decreased brain tissue concentrations of glutamate and aspartate have consistently been reported in both experimental $\underline{13}, \underline{18}, \underline{26}, \underline{27}$ and $\underline{28}$ and human $\underline{29}$ ALF. Results of the present study show that mild hypothermia prevents the reduction of brain glutamate and aspartate associated with experimental ALF. Furthermore, analysis of isotopomer patterns from the ${ }^{13} \mathrm{C}$-NMR spectra reveals that hypothermia leads to normalization of the de novo 
Chatauret, N. et al., 2003. Effects of hypothermia on brain glucose metabolism in acute liver failure: a H/C-nuclear magnetic resonance study. Gastroenterology, 125(3), p.815-824.

synthesis of glutamate via pyruvate dehydrogenase, a key enzyme for oxidative and energy metabolism in the brain, which is expressed in both astrocytes and neurons. Glutamate and aspartate are not only potent excitatory neurotransmitters in that both are involved in brain energy metabolism, serving as substrates/intermediates in the malate-aspartate shuttle (responsible for the transfer of reducing equivalents from the cytosol to mitochondria). Reduced availability of glutamate or aspartate in either cell type, therefore, could result in mitochondrial energy compromise. In the case of glutamate, studies using in vivo cerebral microdialysis have shown that increased release of glutamate in experimental ALF $\underline{8}$ is sensitive to hypothermia.10 Furthermore, the aspartate derivative $\mathrm{N}$ acetylaspartate (NAA), present in high concentrations in the brain, is decreased in frontal cortex at coma stages of encephalopathy under normothermic conditions but is prevented by hypothermia. NAA is a neuronal marker molecule and is involved in brain energy metabolism. $\underline{30}$ Decreased brain concentrations of NAA, therefore, are consistent with neuronal mitochondrial dysfunction in ALF.

In contrast to glutamate and aspartate, ALF because of hepatic devascularization does not result in alterations in either absolute concentrations or synthesis of the inhibitory amino acid GABA. These findings add to a convincing body of evidence that the neural inhibition in both human and experimental ALF $\underline{13}, \underline{18} \underline{26}$ and $\underline{29}$ is not the consequence of altered GABA synthesis in the brain.

It was previously suggested that brain edema in hyperammonemic syndromes such as ALF is the consequence of increased intracellular accumulation of glutamine by the astrocyte. 4 In favor of this hypothesis were reports of increased intracranial pressure in primates infused with ammonia $\underline{26}$ and of increased brain glutamine concentrations in both human $\underline{29}$ and experimental $\underline{27}$ and $\underline{28}$ ALF. Moreover, brain edema because of ammonia infusions was partially prevented by pretreatment with methionine sulfoximine (MSO), a potent inhibitor of glutamine synthetase. $\underline{4}$ and $\underline{31}$ However, MSO treatment may exert multiple effects. For example, MSO also induces massive efflux of glutamine from astrocytes in cultures. 32 In addition, brain glutamine accumulation also occurs in chronic liver failure, a condition not normally associated with brain edema or its clinical consequences. $\underline{4}$ and $\underline{33}$ Therefore, despite several experimental data supporting glutamine as accumulating os molyte in HE, whether or not glutamine accumulation is a major cause for the development of brain edema in ALF is uncertain. $\underline{33}$ Results of the present study confirm an increase in brain glutamine in ALF rats. However, mild hypothermia sufficient to abolish brain edema in these animals did not prevent either the increase in brain glutamine concentration or its de novo synthesis from glucose in astrocytes (i.e., de novo synthesis via the astrocytic enzymes pyruvate carboxylase and glutamine synthetase). A limited capacity of glutamine synthetase was also concluded by Deutz et al.,19 who demonstrated a faster increase of brain ammonia compared with glutamine and by Bosman et al., $\underline{34}$ who observed, after an initial increase of extracellular glutamine during mild HE, a subsequent decrease during severe HE. Direct demonstration of a lack of correlation between the grade of hepatic encephalopathy and glutamine synthetase activity was initially reported by Kanamori et al. $\underline{35}$ using in vivo ${ }^{1} \mathrm{H}$ MRS in a hyperammonemic rat model. Moreover, a previous ${ }^{13} \mathrm{C}$-NMR study could find no significant correlation between brain de novo glutamine synthesis from glucose and grade of encephalopathy or brain edema at coma stages in the hepatic devascularized animal model of ALF.13

In light of the apparently limited capacity of glutamine synthetase, which is thought to be the main detoxification process of ammonia, the question remains of how the brain cells regulate the disposal of excess ammonia in late stages of ALF. In this regard, it has been shown that ammonia can be incorporated into alanine after transamination of glutamate by alanine aminotransferase (ALAT) in both astrocytes and neurons. Consistent with this possibility, alanine has been found to be elevated in the hyperammonemic brain. $\underline{18}, \underline{27}$ and $\underline{36}$ Results of the present study show for the first time that de novo alanine synthesis from glucose is increased as a function of the degree of encephalopathy/brain edema in ALF, which is partly prevented by mild hypothermia. Like lactate formation, synthesis of alanine via ALAT may supplement glycolytic activity, enabling cytosolic ATP production by regeneration of $\mathrm{NAD}^{+}$via subsequent reamination of $\alpha$-ketoglutarate by glutamate dehydrogenase (GDH). It is noteworthy that, in the honeybee retina, which lacks lactate dehydrogenase activity, alanine synthesis in glia fixes ammonia at a rate exceeding glutamine formation, $\underline{37}$ suggesting that ALAT and GDH may operate in a complementary manner to

The final publication is available at http://dx.doi.org/10.1016/S0016-5085(03)01054-0 
oxidize NADH and fix ammonia. Like glutamine, alanine accumulation may increase the cellular content of osmotically active substances, leading to water uptake, cell swelling, and brain edema in ALF. Furthermore, it has been shown that both alanine and glutamine induce hepatocyte swelling, $\underline{38}$ and, in acute HE, a close correlation between CSF alanine with both the degree of neurologic dysfunction $\underline{18}$ and edema $\underline{27}$ was demonstrated, suggesting that increased alanine synthesis may be related to the pathogenesis of brain edema in ALF.

Together, these findings do not support a major role for the accumulation of intracellular glutamine in the astrocyte as a cause of brain edema in ALF. The imperfect correlation of glutamine with brain edema and severity of encephalopathy points to additional mechanisms contributing to brain edema at coma stages. Elevated concentration and synthesis of alanine, which is selectively prevented by mild hypothermia, may play a role in the development of brain edema in ALF. In addition, the correlation between increased glucose flux through the glycolytic pathway (alanine and lactate de novo synthesis) and the severity of encephalopathy and brain edema suggest that a deficit in glucose oxidation and energy metabolism is a major contributor to the pathogenesis of these neurologic complications of ALF and provide a rational argument for the further use of hypothermia in its management.

\section{REFERENCES}

1 A.T. Blei Cerebral edema and intracranial hypertension in acute liver failuredistinct aspects of the same problem Hepatology, 13 (1991), pp. 376-379

2 J.O. Clemmensen, F.S. Larsen, J. Kondrup, B.A. Hansen, P. Ott Cerebral herniation in patients with acute liver failure is correlated with arterial ammonia concentration Hepatology, 29 (1999), pp. 648-653

3 J.C. Szerb, R.F. Butterworth Effect of ammonium ions on synaptic transmission in the mammalian central nervous system Prog Neurobiol, 39 (1992), pp. 135-153

4 J. Cordoba, A.T. Blei Brain edema and hepatic encephalopathy Semin Liver Dis, 3 (1996), pp. 271-280

5 K.V. Rao, M.D. Norenberg Cerebral energy metabolism in hepatic encephalopathy and hyperammonemia Metab Brain Dis, 16 (2001), pp. 67-78

6 K. Knecht, A. Michalak, C. Rose, J.D. Rothstein, R.F. Butterworth Decreased glutamate transporter (GLT-1) expression in frontal cortex of rats with acute liver failure Neurosci Lett, 25 (1997), pp. 1032-1034

7 E. Kosenko, Y. Kaminsky, E. Grau, M.D. Minana, G. Marcaida, S. Grisolia, V. Felipo Brain ATP depletion induced by acute ammonia intoxication in rats is mediated by activation of the NMDA receptor and $\mathrm{Na}+\mathrm{K}(+)$-ATPase J Neurochem, 63 (1994), pp. 2172-2178

8 A. Michalak, C. Rose, J. Butterworth, R.F. Butterworth Neuroactive amino acids and glutamate (NMDA) receptors in frontal cortex of rats with experimental acute liver failure Hepatology, 24 (1996), pp. 908-913

9 P. Traber, M. DalCanto, D. Ganger, A.T. Blei Effect of body temperature on brain edema and encephalopathy in the rat after hepatic devascularization Gastroenterology, 96 (1989), pp. 885-891

10 C. Rose, A. Michalak, M. Pannunzio, N. Chatauret, A. Rambaldi, R.F. Butterworth Mild hypothermia delays the onset of coma and prevents brain edema and extracellular brain glutamate accumulation in rats with acute liver failure Hepatology, 31 (2000), pp. 872-877

11 N. Chatauret, C. Rose, G. Therrien, M. Pannunzio, R.F. Butterworth Mild hypothermia prevents cerebral edema and CSF lactate accumulation in acute liver failure Metab Brain Dis, 16 (2001), pp. 95-102

The final publication is available at http://dx.doi.org/10.1016/S0016-5085(03)01054-0 
12 R. Jalan, S.W.M. Dalmink, A. Olde Lee, P.C. Hayes Moderate hypothermia for uncontrolled intracranial hypertension in acute liver failure Lancet, 354 (1999), pp. 1164-1168

13 C. Zwingmann, N. Chatauret, D. Leibfritz, R.F. Butterworth Selective increase of brain lactate synthesis in experimental acute liver failureresults of a $\left[{ }^{1} \mathrm{H}^{-13} \mathrm{C}\right]$ nuclear magnetic resonance study Hepatology, 37 (2003), pp. $420-428$

14 S.H. Lee, B. Fischer Portacaval shunt in the rat Surgery, 50 (1961), pp. 668-672

15 A. Marmarou, W. Poll, H. Bhagavan A simple gravimetric technique for measurement of cerebral edema J. Neurosurg, 49 (1978), pp. 530-537

16 S.G. Dienst An ion exchange method for plasma ammonia concentration J Lab Clin Med, 58 (1961), pp. 149-155

17 C. Zwingmann, C. Richter-Landsberg, A. Brand, D. Leibfritz NMR spectroscopic study on the metabolic fate of [3(13)C]alanine in astrocytes, neurons, and coculturesimplications for glia-neuron interactions in neurotransmitter metabolism Glia, 32 (2000), pp. 286-303

18 A.M. Mans, M.R. DeJoseph, R.A. Hawkins Metabolic abnormalities and grade of encephalopathy in acute hepatic failure J Neurochem, 63 (1994), pp. 1829-1838

19 N.E.P. Deutz, A.A. De Graaf, J.G. De Haan, W.M.M.J. Bovée, R.A.F.M. Chamuleau In vivo brain ${ }^{1}$ H-NMR spectroscopy $\left({ }^{1} \mathrm{H}-\mathrm{NMRS}\right)$ during acute hepatic encephalopathy (HE) P.B. Soeters, J.H.P. Wilson, A.J. Meijer, E. Holm (Eds.), Advances in ammonia metabolism and hepatic encephalopathy, chapter 57, Excerpta Medica, Amsterdam (1988), pp. 439-446

20 F. Staub, A. Baethmann, J. Peters, H. Weigt, O. Kempski Effects of lactacidosis on glial cell volume and viability J Cereb Blood Flow Metab, 10 (1990), pp. 866-876

21 S.L. Nyberg, F.B. Cerra, R. Gruetter Brain lactate by magnetic resonance spectroscopy during fulminant hepatic failure in the dog Liver Transpl Surg, 4 (1998), pp. 158-165

22 D.W. McCandless, S. Schenker Effect of acute ammonia intoxication on energy stores in the cerebral reticular activating system Exp Brain Res, 44 (1981), pp. 325-330

23 M. Matsuoka, H. Igisu, K. Kohriyama, N. Inoue Effects of ammonia on brain energy metabolites-dose-dependent alterations J Neurochem, 55 (1990), pp. 354-355

24 T.E. Bates, S.R. Williams, A.L. Busza, D.G. Gadian, E. Proctor A ${ }^{31} \mathrm{P}$ nuclear magnetic resonance study in vivo of metabolic abnormalities in rats with acute liver failure NMR Biomed, 1 (1988), pp. 67-73

25 J.C.K. Lai, A.J. Cooper Neurotoxicity of ammonia and fatty acidsdifferential inhibition of mitochondrial dehydrogenases by ammonia and fatty acyl coenzyme A derivatives Neurochem Res, 16 (1991), pp. 795-803

26 T.M. Voorhies, M.E. Ehrlich, T.E. Duffy, C.K. Petito, F. Plum Acute hyperammonemia in the young primatephysiologic and neuropathologic correlates Pediatr Res, 17 (1983), pp. 970-975

27 M. Swain, R.F. Butterworth, A.T. Blei Ammonia and related amino acids in the pathogenesis of brain edema in acute ischemic liver failure in rats Hepatology, 15 (1992), pp. 449-453

28 D.K. Bosman, N.E. Deutz, A.A. De Graaf, R.W. vd Hulst, H.M. Van Eijk, W.M. Bovee, M.A. Maas, G.G. Jorning, R.A. Chamuleau Changes in brain metabolism during hyperammonemia and acute liver failureresults of a comparative ${ }^{1} \mathrm{H}-\mathrm{NMR}$ spectroscopy and biochemical investigation Hepatology, 12 (1990), pp. 281-290 
29 C.O. Record, B. Buxton, R.A. Chase, G. Curzon, I.M. Murray-Lyon, R. Williams Plasma and brain amino acids in fulminant hepatic failure and their relationship to hepatic encephalopathy Eur J Clin Invest, 6 (1976), pp. 387-394

30 J.B. Clark N-acetyl aspartatea marker for neuronal loss or mitochondrial dysfunction Dev Neurosci, 20 (1998), pp. 271-276

31 H. Takahashi, R.C. Koehler, S.W. Brusilow, R.J. Traysman Inhibition of brain glutamine accumulation prevents cerebral edema in hyperammonemic rats Am J Physiol, 261 (1991), pp. H825-H829

$32 \mathrm{~J}$. Albrecht, M.D. Norenberg L-methionine-DL-sulfoximine induces massive efflux of glutamine from cortical astrocytes in primary culture Eur J Pharmacol, 182 (1990), pp. 587-589

33 J. Albrecht, M. Dolinska Glutamine as a pathogenic factor in hepatic encephalopathy J Neurosci Res, 65 (2001), pp. $1-5$

34 D.K. Bosman, N.E. Deutz, M.A. Maas, H.M. van Eijk, J.J. Smit, J.G. de Haan, R.A. Chamuleau Amino acid release from cerebral cortex in experimental acute liver failure, studied by in vivo cerebral cortex microdialysis J Neurochem, 59 (1992), pp. 591-599

35 K. Kanamori, B.D. Ross, J.C. Chung, E.L. Kuo Severity of hyperammonemic encephalopathy correlates with brain ammonia level and saturation of glutamine synthetase in vivo J Neurochem, 67 (1996), pp. 1584-1594

36 W. Hilgier, M. Zielinska, H.D. Borkowska, R. Gadamski, M. Walski, S.S. Oja, P. Saransaari, J. Albrecht Changes in the extracellular profiles of neuroactive amino acids in the rat striatum at the asymptomatic stage of hepatic failure J Neurosci Res, 56 (1999), pp. 76-84

37 M. Tsacopoulos, C.L. Poitry-Yamate, S. Poitry, P. Perrottet, A.L. Veuthey The nutritive function of glia is regulated by signals released by neurons Glia, 1 (1997), pp. 84-91

38 D. Haussinger Regulation and functional significance of liver cell volume Prog Liver Dis, 14 (1996), pp. 29-53

Supported by a grant from The Canadian Institutes of Heath Research. 